\section{Revista}

Ibero-Americana de Estratégıa

\title{
RACIOCÍNIO EFFECTUAL E RACIOCÍNIO CAUSAL NA CRIAÇÃO DE NOVOS NEGÓCIOS: UM ESTUDO DE CASO
}

EFFECTUAL REASONING AND CAUSAL REASONING IN CREATING NEW BUSINESSES: A CASE STUDY

\section{RAZONAMIENTO EFFECTUAL Y RAZONAMIENTO CAUSAL EN LA CREACIÓN DE NUEVOS NEGOCIOS}

\section{Juan Miguel Rosa González}

Mestre em Administração pela Universidade Federal do Rio Grande do Norte - UFRN

Professor da Faculdade de Ciências Empresariais de Natal - FACEN

E-mail: jmrosag@yahoo.es (Brasil)

\section{Miguel Eduardo Moreno Añez}

Doutor em Administração de Empresas pela Fundação Getulio Vargas - FGV

Professor da Universidade Federal do Rio Grande do Norte - UFRN

E-mail: anez1957@yahoo.com.br (Brasil)

\section{Hilka Vier Machado}

Doutora em Engenharia de Produção pela Universidade Federal de Santa Catarina - UFSC

Professora do Mestrado em Administração da Universidade Estadual de Maringá - UEM

E-mail: hilkavier@yahoo.com (Brasil) 
Raciocínio Effectual e Raciocínio Causal na Criação de Novos Negócios: Um Estudo de Caso

\title{
RACIOCÍNIO EFFECTUAL E RACIOCÍNIO CAUSAL NA CRIAÇÃO DE NOVOS NEGÓCIOS: UM ESTUDO DE CASO
}

\section{RESUMO}

Esse artigo foca o processo de criação de novos negócios à luz da abordagem effectuation, que explica o fenômeno do empreendedorismo com base em postulados substancialmente diferentes aos da abordagem causal tradicional. Depois de uma descrição dos pressupostos básicos do raciocínio effectual e das diferenças principais entre ele e o raciocínio causal, esse trabalho apresenta o caso do grupo Vamtec, organização de capital nacional criada na década de 1980 e que atua no desenvolvimento, produção e comercialização de materiais e serviços para a siderurgia. Por meio de entrevista semiestruturada em profundidade com o empreendedor que idealizou o negócio, são descritos os principais acontecimentos que tiveram lugar durante as fases iniciais do projeto. Os resultados desse estudo de caso são discutidos na sequência e imediatamente se apresentam as considerações finais do trabalho, entre as quais se destaca a relação entre os meios que o empreendedor dispunha na época e a formatação do novo negócio, além da preferência por uma estratégia de desenho sobre uma estratégia de decisão e a priorização de parcerias estratégicas sobre a realização de pesquisas de mercado formais, aspectos todos eles contemplados pela abordagem effectual.

Palavras-chave: Criação de Empresas; Effectuation; Empreendedorismo.

\section{EFFECTUAL REASONING AND CAUSAL REASONING IN CREATING NEW BUSINESSES: A CASE STUDY}

\begin{abstract}
This article focuses on the process of new business creation, considering the effectuation approach, which explains the phenomenon of entrepreneurship in a different perspective than the traditional causal approach. A case study, using a description of the effectual approach assumptions, about the subject is presented in order to explore the logic of the business creation process. The case discusses a Brazilian organization created in 1980 to produce materials and services in the steel industry. Through a structured interview with the entrepreneur who idealized the business, the main events in the early stages of the project are described. The results show the relationship between the entrepreneur's means available at the time of the enterprise creation and the new business design. In addition, the entrepreneur preferred a strategy of drawing instead of a decision one, and gave priority to strategic partnerships as a substitute of formal market research. All these aspects are covered by the effectual approach.
\end{abstract}

Keywords: Business Creation; Effectuation; Entrepreneurship. 


\section{RAZONAMIENTO EFFECTUAL Y RAZONAMIENTO CAUSAL EN LA CREACIÓN DE NUEVOS NEGOCIOS}

\section{RESUMEN}

Este artículo enfoca el proceso de creación de nuevos negocios a la luz del acercamiento effectuation, que explica el fenómeno del espíritu empresarial basado en postulados substancialmente diferentes a los del acercamiento causal tradicional. Después de una descripción de las presuposiciones básicas del razonamiento effectual y de las diferencias principales entre éste y el razonamiento causal, el trabajo presenta el caso del grupo Vamtec, organización de capital nacional creada en la década de 1980 y que actúa en el desarrollo, producción y comercialización de materiales y servicios para la siderurgia. A través de entrevista semi-estructurada en profundidad con el empresario que idealizó el negocio, se describen los eventos principales que ocurrieron durante las fases iniciales del proyecto. Los resultados de este estudio de caso son discutidos a seguir e inmediatamente se presentan las consideraciones finales del trabajo, entre las cuales se destaca la relación entre los medios que el emprendedor tenía en esa época y el formato del nuevo negocio, además de la preferencia para una estrategia de diseño sobre una estrategia de decisión y la priorización de sociedades estratégicas para la realización de investigaciones de mercado formales, todos estos aspectos son contemplados por el enfoque effectual.

Palabras-clave: Creación de Empresas; Effectuation; Espíritu Empresarial. 
Raciocínio Effectual e Raciocínio Causal na Criação de Novos Negócios: Um Estudo de Caso

\section{INTRODUÇÃO}

O fenômeno do empreendedorismo recebe cada dia mais atenção em programas de pósgraduação no mundo (DEW et al, 2009), na tentativa de capturar, por meio da compreensão de como empreendedores pensam e atuam quando estão construindo novos negócios, a essência da atividade de empreender. Pesquisadores e docentes deparam-se, porém, com uma dificuldade de partida: a carência de definições e limites claros para o campo de estudo do empreendedorismo (Venkataraman, 1997). Superando essa indefinição, Venkataraman (1997) conclui que o estudo do empreendedorismo "ocupa-se em compreender como, na ausência de mercados existentes para futuros produtos e serviços, estes produtos e serviços chegam a existir", configurando-se assim como objetivo primordial dos estudos nessa área "entender como oportunidades para tornar realidade 'futuros' produtos e serviços são descobertas, criadas e exploradas, por quem, e com quais conseqüências" (Venkataraman, 1997, p. 120).

Ancorados nesse posicionamento, Dew et al (2008, p. 41) apontam uma diferença central entre as empresas preexistentes e os novos negócios criados por empreendedores, ao destacar que “empresas e mercados não são assumidos como dados no empreendedorismo", dado que "ou as empresas são novas, ou os mercados são novos, ou ambos são novos". Os empreendedores, assim, não se defrontam tanto com problemas de decisão como de desenho (Sarasvathy, 2003, Dew et al, 2008). O conceito de desenho, na visão desses autores -embasada na obra de Simon (1981) sobre as ciências do artificial- não está ligado ao planejamento de ações para atingir objetivos predeterminados, e mas à produção de novidades, "sejam elas novas empresas, novos mercados, novas tecnologias ou inclusive novas sociedades" (Dew et al, 2008, p. 42), em um processo criativo que não se apóia em um raciocínio causal, e sim effectual.

Propõe-se a analisar, por meio desse artigo, por meio de um estudo de caso, a lógica adotada por um empreendedor brasileiro durante o processo de criação de um novo negócio, com o objetivo de compreender a predominância, nesse processo, de um raciocínio causal tradicional ou de um raciocínio effectual (Sarasvathy, 2001, 2003; Sarasvathy \& Dew, 2005; Dew, Read, Sarasvathy \& Wiltbank, 2008; Dew, Read, Sarasvathy \& Wiltbank, 2009). Para tanto, foi conduzida uma entrevista em profundidade com o sujeito de estudo, um empreendedor de 52 anos de idade e com experiência empresarial, cujos resultados são apresentados e discutidos à luz da teoria depois de uma revisão da literatura específica sobre a abordagem effectuation. Na sequência, são apresentadas as considerações finais do trabalho e sugeridas pesquisas que podem aprofundar a compreensão do processo de criação de novos negócios por empreendedores.

Revista Ibero-Americana de Estratégia - RIAE, São Paulo, v. 10, n. 2, p. 140-158, mai./ago. 2011. 


\section{RACIOCÍNIO CAUSAL VERSUS RACIOCÍNIO EFFECTUAL}

Sarasvathy (2001, p. 2) opõe o termo "effectual" ao termo "causal", salientando que, enquanto o raciocínio causal parte de um objetivo pré-determinado e um conjunto de meios disponíveis para procurar a melhor forma de atingir esse objetivo, o raciocínio effectual não começa com um objetivo específico, e sim com um conjunto de meios a partir dos quais irão surgindo diferentes objetivos, dependendo das pessoas que sejam incorporadas ao empreendimento com o passar do tempo. A autora esclarece que apesar de serem opostas, essas duas formas de raciocínio ou essas duas lógicas- não são mutuamente excludentes, sendo o mais provável que o empreendedor utilize cada uma delas em diferentes momentos do processo de criação e desenvolvimento de novos negócios, com preferência para o raciocínio effectual nos estágios iniciais do processo empreendedor. Sarasvathy (2001) resume as diferenças fundamentais entre os dois tipos de raciocínio na figura 1 :

Figura 1- Diferenças entre raciocínio causal e effectual.
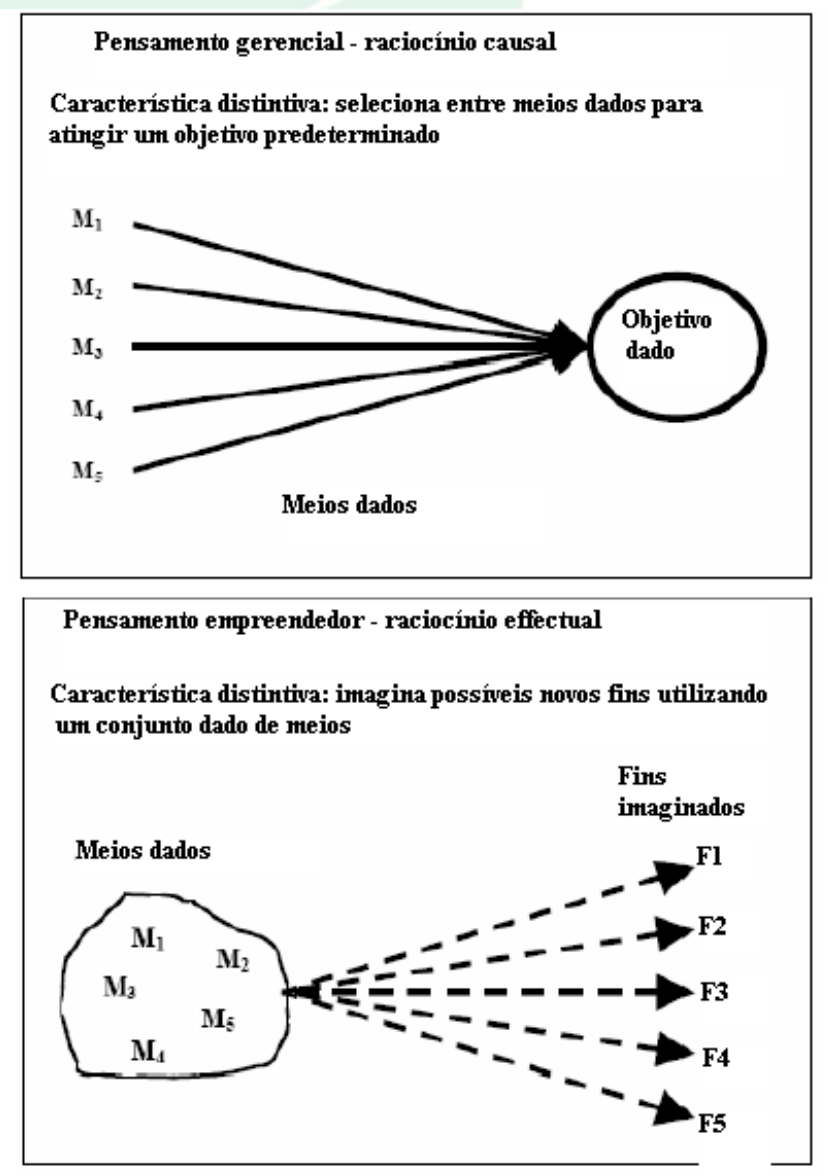

Revista Ibero-Americana de Estratégia - RIAE, São Paulo, v. 10, n. 2, p. 140-158, mai./ago. 2011. 
Conforme se observa na figura 1, enquanto o raciocínio causal enfatiza as decisões que os empreendedores devem adotar para atingir um objetivo predeterminado, o raciocínio effectual enfatiza a criação de possíveis objetivos, tendo como base os meios disponíveis e a negociação entre os stakeholders envolvidos no projeto. Na explicação de Dew et al (2008, p. 43):

As estratégias de desenho permitem que os objetivos surjam das interações entre os stakeholders [...], que buscam modelar e fabricar o ambiente (inicialmente) local. Nesta formulação, tanto a empresa empreendedora quanto o seu ambiente local são, portanto, um efeito residual de um processo de desenho que se utiliza de uma lógica effectual.

A lógica effectual se sustenta em uma visão do mundo - e dos ambientes de negócios - como uma realidade em construção, cuja modelagem considera a ação humana extremamente importante. Disso decorre uma diferença fundamental entre o raciocínio causal e o effectual durante o processo empreendedor: enquanto a lógica causal se propõe a escolher diferentes meios para criar um efeito específico, a lógica effectual visa criar possíveis efeitos usando um conjunto específico de meios (Dew et al, 2008).

Independentemente de onde e quando se produz o fenômeno do empreendedorismo, o empreendedor dispõe sempre de três tipos de meios: a) quem ele é - características pessoais, gostos e habilidades; b) o que ele sabe - educação, experiência e expertise; e c) quem ele conhece - redes sociais e profissionais (Sarasvathy, 2001). Sarasvathy e Dew (2005) oferecem uma explicação ampliada sobre essas três categorias de meios disponíveis para o empreendedor:

a) Quem ele é: a lógica da identidade versus a lógica das preferências. Defrontados com ambiguidade de objetivos, os empreendedores tendem a explicar a escolha de determinado curso de ação mais com base na própria identidade do que nas suas preferências, mesmo quando não estão claras as consequências dessas ações, isto é, quando não há um vínculo claro de causa-efeito entre ação e resultado esperado. Em palavras de Sarasvathy e Dew (2005, p. 393):

A diferença reside na relação entre preferências por determinados resultados e preferências por determinados cursos de ação. Quando a preferência por um determinado resultado está claramente conectada com a preferência por um determinado curso de ação que leva a esse resultado as preferências podem ser suficientes para subsidiar a tomada de decisão. Porém, o raciocínio a partir da identidade funciona também quando não há vínculo causal entre escolha e conseqüência, quando um abismo parece se abrir entre escolha e conseqüência, ou quando o empreendedor se sente apaixonadamente atraído por um determinado curso de ação mesmo sem ter a menor idéia se ele levará ou não a resultados desejáveis.

Revista Ibero-Americana de Estratégia - RIAE, São Paulo, v. 10, n. 2, p. 140-158, mai./ago. 2011. 
b) O que ele sabe: a lógica da ação versus a lógica da crença. Empreendedores experientes preferem, como forma para coletar dados sobre o ambiente, a ação direta sobre o mesmo, mais do que informações baseadas em predições. Do mesmo modo, eles tendem a ignorar estimativas probabilísticas quando analisam oportunidades de negócio. Como explicam Sarasvathy e Dew (2005, p. 398), “eles enfatizam o lado positivo da imprevisibilidade, o fato de que surpresas podem ser agradáveis; o de que as contingências podem oferecer oportunidades imprevistas". Desse modo, como salientam Reat et al (2011), eles constroem e criam as oportunidades usando os meios que dispõem.

c) Quem ele conhece: a lógica dos compromissos versus a lógica das transações.

$\mathrm{Na}$ lógica effectual, há espaço para a docilidade, em detrimento do oportunismo nas relações, como também há espaço para a ambiguidade de preferências entre os atores envolvidos. A noção de docilidade, introduzida por Simon (1991, 1993, 1997) e recuperada por Augier e Sarasvathy (2004), refere-se à tendência humana a se embasar em sugestões, recomendações e informações de outros durante a tomada de decisão.

Com isso, empreendedores experientes partem da própria identidade, conhecimentos, experiências e relações sociais para, numa sequência de interações e compromissos entre os stakeholders que vão sendo incorporados ao projeto, para modelar, de forma dinâmica, o novo negócio e a organização a ele vinculado, como salientam Sarasvathy e Dew (2005, p. 402):

\begin{abstract}
Os empreendedores experientes [...] procedem através de uma cadeia de interações com os stakeholders que conduz a compromissos específicos com um projeto potencial que só é determinado através do próprio processo de buscar esses compromissos. Esta cadeia de interações effectual põe em marcha dois ciclos - um ciclo expansivo de meios e recursos mobilizados que cada novo stakeholder acrescenta ao negócio, e outro ciclo de restrições sobre os possíveis objetivos e resultados do projeto que converge com os objetivos da organização resultante. Cada novo stakeholder tem alguma coisa a dizer sobre no que o artefato efetivamente resultará, mais do que sobre se ele será ou quão valioso ele será.
\end{abstract}

Os três aspectos ressaltados nos parágrafos anteriores constituem o foco central da abordagem effectuation e estão articulados entre si. Essa articulação produz um ciclo expansivo de recursos, como pode ser visualizado na figura 2 : 
Figura 2 - Processo dinâmico de interações effectual.

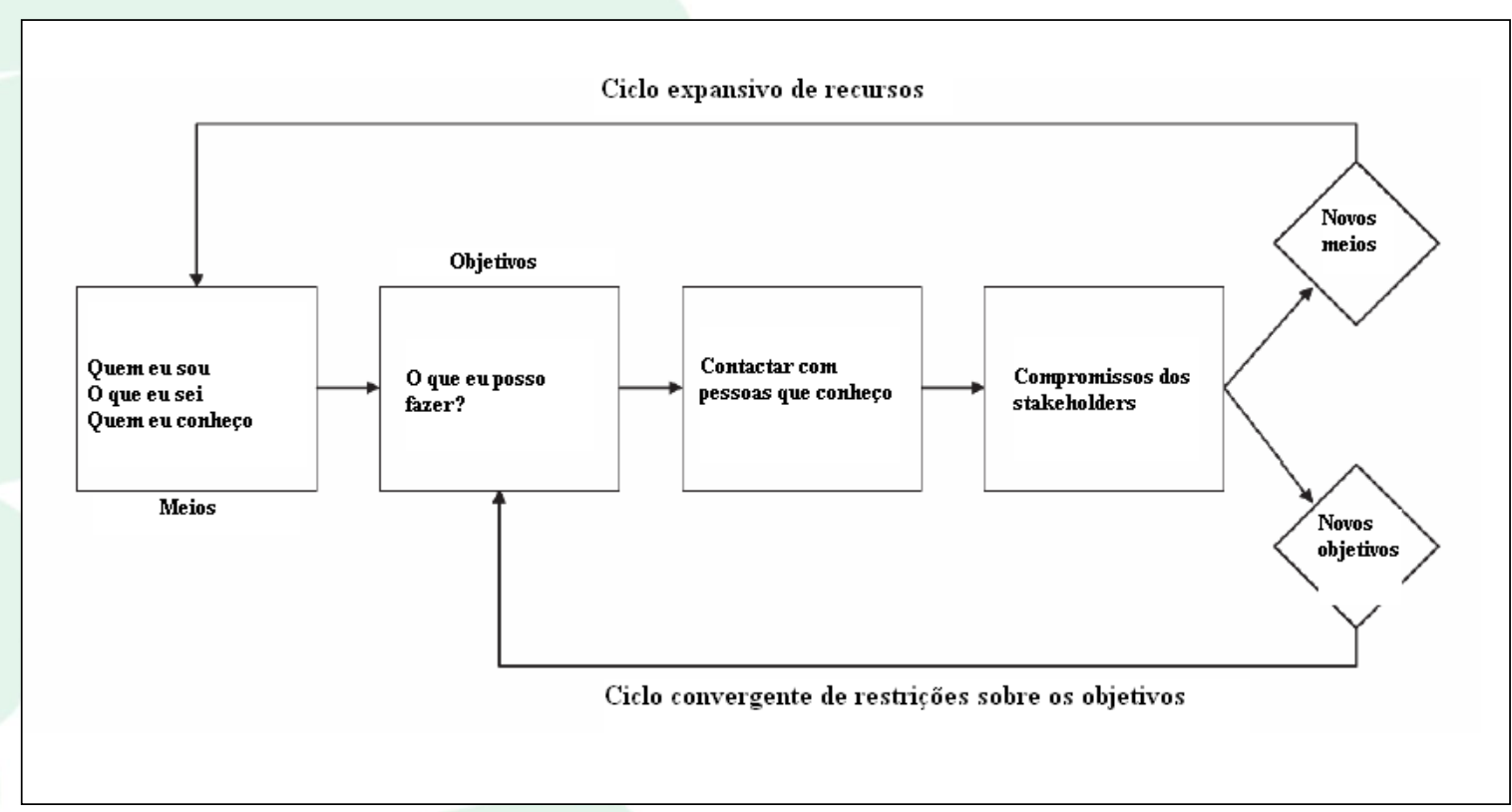

\section{PRINCÍPIOS DO RACIOCÍNIO EFFECTUAL}

Sarasvathy (2001) resume o raciocínio effectual em três grandes princípios: perdas toleráveis; parcerias estratégicas e exploração de contingências. Read et al (2011) acrescentam como primeiro princípio o de começar com os meios disponíveis, que correspondem aos comentados anteriormente.

\subsection{PRINCÍPIO DAS PERDAS TOLERÁVEIS}

Enquanto tradicionalmente, tanto no campo do marketing quanto no da administração é considerado que a empresa deve focar segmentos de mercado com alto potencial de retorno financeiro, para a abordagem effectuation os empreendedores tendem a priorizar mercados que minimizem o dispêndio de tempo, esforço e dinheiro. Com isso, eles não focam os retornos desejados, mas o quanto estão dispostos a perder (Read et al. 2011). 


\subsection{PRINCÍPIO DAS PARCERIAS ESTRATÉGICAS}

Dado que no raciocínio effectual empreendedores não pressupõem a existência de um mercado para a sua ideia, nada justifica a realização de análises competitivas tradicionais. Por isso, eles enfatizam a construção de parcerias estratégicas com potenciais stakeholders, incluindo-se desde clientes até possíveis concorrentes.

\subsection{PRINCÍPIO DA EXPLORAÇÃO DE CONTINGÊNCIAS}

Em lugar de evitar as surpresas -premissa fundamental no raciocínio causal- a lógica effectual considera a transformação dos acontecimentos inesperados, ou seja contingências, em possibilidades de novas oportunidades.

Sob esses três princípios respalda-se a lógica fundamental do raciocínio effectual: na medida em que o futuro pode ser controlado, não é necessário predizê-lo (Sarasvathy, 2001). Nessa visão, a atitude do empreendedor difere da atitude do gerente e do estrategista tradicional "por acreditar em um futuro ainda por fazer, que pode ser substancialmente modelado pela ação humana" (Sarasvathy, 2001, p. 9). O controle não preditivo próprio da abordagem effectual consiste em priorizar aqueles elementos sobre os quais o empreendedor e os stakeholders podem ter controle em um determinado momento (Wiltbank, Dew, Read \& Sarasvathy, 2006), dispensando -pelo menos nas fases iniciais do empreendimento- informações preditivas. Essa e outras diferenças substanciais entre o raciocínio effectual e o causal foram resumidas por Sarasvathy e Dew (2005), e são apresentadas no quadro 1:

\begin{tabular}{|c|c|c|}
\hline ASSUNTO & POSIÇÃo CAUSAL & POSIÇÃO EFFECTUAL \\
\hline Visão do futuro & $\begin{array}{c}\text { Predição. O futuro é uma } \\
\text { continuação do passado e pode } \\
\text { ser razoavelmente previsto. }\end{array}$ & $\begin{array}{c}\text { Desenho. O futuro é contingente } \\
\text { às ações propositais dos agentes. } \\
\text { E resultado das escolhas e dos } \\
\text { acordos entre os agentes. }\end{array}$ \\
\hline CONSTRUTOS RELACIONADOS A DECISÕES INDIVIDUAIS \\
\hline Dados & Objetivos são dados & $\begin{array}{c}\text { Meios (quem eu sou, o que eu } \\
\text { sei, quem eu conheço) são } \\
\text { dados. }\end{array}$ \\
\hline Agenda de decisão & $\begin{array}{c}\text { Recursos. Que recursos devo } \\
\text { acumular para atingir os } \\
\text { objetivos? }\end{array}$ & $\begin{array}{c}\text { Efeitos. Quais efeitos posso criar } \\
\text { com os meios de que disponho? }\end{array}$ \\
\hline
\end{tabular}


Raciocínio Effectual e Raciocínio Causal na Criação de Novos Negócios: Um Estudo de Caso

\begin{tabular}{|c|c|c|}
\hline Bases para a ação & $\begin{array}{l}\text { Mundos desejados. A visão de } \\
\text { um mundo desejado determina } \\
\text { os objetivos; os objetivos } \\
\text { determinam subobjetivos, } \\
\text { compromissos e ações. }\end{array}$ & $\begin{array}{c}\text { Mundos possíveis. Os meios e os } \\
\text { compromissos dos stakeholders } \\
\text { determinam possíveis } \\
\text { subobjetivos. Os objetivos } \\
\text { emergem pela agregação de } \\
\text { subobjetivos. } \\
\end{array}$ \\
\hline Bases do compromisso & $\begin{array}{c}\text { Deve. Faça o que você deve } \\
\text { fazer com base em análises e } \\
\text { maximização. }\end{array}$ & $\begin{array}{c}\text { Pode. Faça o que você é capaz } \\
\text { de fazer com base na imaginação } \\
\text { e na satisfação. }\end{array}$ \\
\hline Aquisição de stakeholders & $\begin{array}{l}\text { Visão instrumental dos } \\
\text { stakeholders. Os objetivos do } \\
\text { projeto determinam quem é se } \\
\text { incorporará a ele. }\end{array}$ & $\begin{array}{c}\text { Visão instrumental dos } \\
\text { objetivos. Quem é incorporado } \\
\text { ao projeto determina seus } \\
\text { objetivos. Nenhum dos } \\
\text { participantes ao se integrar no } \\
\text { projeto tem noção sobre qual } \\
\text { será o objetivo. } \\
\end{array}$ \\
\hline \multicolumn{3}{|c|}{ CONSTRUTOS EM TERMOS DE RESPOSTAS AO AMBIENTE } \\
\hline Predisposição ao risco & $\begin{array}{l}\text { Retorno esperado. Calcule o } \\
\text { potencial positivo e procure } \\
\text { (ajustando o risco) a melhor } \\
\text { oportunidade. }\end{array}$ & $\begin{array}{l}\text { Perdas toleráveis. Calcule o } \\
\text { potencial negativo e arrisque } \\
\text { apenas o que pode perder. }\end{array}$ \\
\hline Predisposição às contingências & $\begin{array}{c}\text { Evitar. As surpresas podem ser } \\
\text { desagradáveis. Portanto, invista } \\
\text { em técnicas para evitá-las ou } \\
\text { neutralizá-las. }\end{array}$ & $\begin{array}{c}\text { Explorar. As surpresas podem } \\
\text { ser positivas. Portanto, invista } \\
\text { em técnicas que são abertas às } \\
\text { surpresas e transforme-as em } \\
\text { novas oportunidades. } \\
\end{array}$ \\
\hline Atitude perante sucesso/fracasso & $\begin{array}{l}\text { Resultados. Sucesso e fracasso } \\
\text { são resultados diferenciados que } \\
\text { devem ser, respectivamente, } \\
\text { buscados e evitados. }\end{array}$ & $\begin{array}{l}\text { Processo. Sucesso e fracasso são } \\
\text { inputs em um processo que } \\
\text { precisa ser gerenciado, de forma } \\
\text { que os fracassos sejam superados } \\
\text { e os sucessos acumulados. }\end{array}$ \\
\hline
\end{tabular}

Quadro 1- Contrastando os raciocínios effectual e causal.

Observa-se que o raciocínio effectual foca o que pode ser feito a partir dos meios disponíveis, e não -como ocorre no raciocínio causal- o que deve ser feito para se atingir objetivos previamente formulados. A lógica da effectuation prefere parcerias e compromissos entre stakeholders do que análises competitivas tradicionais e enfatiza critérios de decisão fundamentados, não na predição do futuro como uma continuação do passado, mas sim na criação de um futuro que pode ser modelado pelas ações dos indivíduos.

\section{PROCEDIMENTOS METODOLÓGICOS}

Esse trabalho caracteriza-se, quanto aos seus objetivos, como pesquisa exploratória (Malhotra, 2004; Gil, 2009) e descritiva (Cervo; Bervian, 2004; Vergara, 2004), dado que visa proporcionar uma maior compreensão do fenômeno estudado, expondo suas características 
peculiares e descobrindo, até onde seja possível, a sua natureza. O procedimento utilizado foi o estudo de caso por meio de pesquisa de campo (Andrade, 1994) para o levantamento de dados primários, analisados posteriormente mediante abordagem qualitativa. O estudo de caso é uma pesquisa que investiga um fenômeno em seu contexto natural e é útil, principalmente, para auxiliar na elaboração e no aprimoramento de teorias e para dar resposta a perguntas do tipo "como?" e "por quê?”, visando melhor compreensão da natureza do processo estudado (Yin, 1994). Pode também ser utilizado como etapa exploratória na pesquisa de fenômenos pouco investigados (Yin, 1994).

A escolha do sujeito de estudo, empreendedor com vasta experiência empresarial, seguiu principalmente o critério de acessibilidade, como também pelo fato de empreender em um ramo dominado por grandes empresas, representando assim uma situação de grande incerteza para empreender. Em primeiro lugar, vale destacar que ao longo dos últimos 25 anos -entre 1985 e 2010o sujeito de estudo, o empreendedor Pedro de Moraes Heltai, esteve envolvido diretamente, como sócio fundador, na criação de três empresas diferentes, sendo o caso discutido nesse artigo -a criação do Grupo Vamtec- que resultou na empresa de maior porte e longevidade. Como segunda característica, encontra-se a formação estritamente técnica desse empreendedor, que em nenhum momento cursou ensino superior em gestão empresarial. Finalmente, deve-se acrescentar que ele tem se dedicado a enfrentar a criação de empresas, o que propicia uma característica importante para estudar estágios iniciais da criação de novos projetos empresariais, objeto de análise desse estudo.

Os dados foram coletados por meio de entrevista semiestruturada com o sujeito de estudo em junho de 2010. Solicitou-se ao empreendedor que descrevesse sobre como foram os estágios iniciais do principal empreendimento que criou, desde o surgimento da ideia até a consolidação da empresa, a fim de compreender a lógica (causal ou effectual) que orientou suas ações. Posteriormente, a entrevista foi gravada e transcrita para fins de análise dos dados.

Para o tratamento dos dados foi adotado o procedimento de codificação dos dados, conforme sugerem Bauer e Gaskell (2008). As categorias de análise foram: clareza nos meios, estratégia de desenho versus estratégia de decisão e parcerias estratégicas com foco nas contingências. 
Raciocínio Effectual e Raciocínio Causal na Criação de Novos Negócios: Um Estudo de Caso

\title{
5 APRESENTAÇÃO E ANÁLISE DOS DADOS
}

\subsection{APRESENTAÇÃO DO CASO}

O caso analisado foi a criação, na década de 1980, de uma empresa de produtos e serviços para a indústria siderúrgica, embrião do que, atualmente, é o Grupo Vamtec, conglomerado de capital nacional que conta com seis empresas, quatro plantas de produção no Brasil -nos estados de Espírito Santo, Bahia, Minas Gerais e Pará- e um total de 530 funcionários, além de duas unidades de negócios na Venezuela e no Peru. O Grupo Vamtec, que teve um faturamento de R\$ 105.932.347,00 em 2010, atua no desenvolvimento, produção e comercialização de materiais e serviços para a siderurgia, indústrias produtoras de alumínio, ferro-ligas, vidros e fundições, além de contar com frota especializada em transporte pressurizado e a granel.

\subsection{CLAREZA NOS MEIOS}

Após uma onda de demissões em massa na empresa onde trabalhava, e a despeito de não ter sido afetado pela redução de pessoal, Pedro Heltai resolveu criar o seu próprio negócio. Corria o ano de 1985. Sua ideia do empreendimento era clara desde o início, como também as pessoas que seriam necessárias para torná-la realidade:

\begin{abstract}
Pensei em criar uma empresa concorrente daquela onde trabalhava, porque era a única coisa que eu sabia fazer. Eu era da área de pesquisa, e precisava de alguém na produção, alguém que tomasse conta das vendas e da assistência técnica e alguém para as finanças. Eu sabia exatamente quem deveria estar em cada uma dessas áreas. Eram meus colegas na empresa onde trabalhava. Fui atrás de cada um deles e em um mês consegui convencê-los, mostrando-lhes que com o conhecimento da equipe que eu imaginava, o empreendimento era possível, mesmo sem dispormos de capital. O especialista em produção desistiu no último momento e, realmente, fez muita falta: impossibilitou que tivéssemos a qualidade de produto desejada desde o início.
\end{abstract}

Observa-se uma estreita ligação entre a ideia do empreendimento e os meios necessários para alcançá-lo. Mas o que pareceria uma lógica causal tradicional (objetivo dado e seleção minuciosa dos meios mais adequados para a sua consecução) pode ser lido de outra forma: meios disponíveis (conhecimento técnico altamente especializado e relações profissionais e pessoais com possíveis stakeholders) dos quais decorre o objetivo de criar uma empresa como aquela na qual o empreendedor e os que viriam a serem seus sócios trabalhavam. Poder-se-ia dizer que o objetivo do empreendimento nunca teria existido sem a existência prévia de um conjunto muito específico de meios -conhecimentos e relacionamentos- que determinaram a forma que esse objetivo assumiria. 
Observa-se, assim, uma sequência de acontecimentos condizente com a abordagem effectual: não é o objetivo que predetermina a busca por determinados recursos, e assim a disponibilidade desses recursos é que determina o que o empreendimento deverá ser (Sarasvathy, 2001). Além disso, notase que os meios disponíveis para o empreendedor constituem o ponto de partida do empreendimento, mas o melhor delineamento e a decisão de criação foram sendo construídas passo a passo, como comentam Read et al (2011), sobre o preparo de empreendedores para o "mergulho"e como será observado a seguir.

\subsection{ESTRATÉGIA DE DESENHO VERSUS ESTRATÉGIA DE DECISÃO}

Operando em um setor bem delimitado - cinco empresas ofereciam na época produtos de siderurgia para um total de treze clientes dessa indústria-, a Vamtec tentou ganhar espaço no mercado com uma política de preços baixos. Mas a reação das empresas concorrentes, que resolveram abaixar também os seus preços, ameaçava a sobrevivência da empresa recém-criada. Como consequência dessa contingência, novo direcionamento foi dado ao empreendimento, caracterizando-se como raciocínio effectual que explora as contingências (Sarasvathy, 2001). Então, a solução foi investir em um produto novo, escassamente representativo para as grandes empresas já consolidadas, mas que permitiu à Vamtec conquistar um espaço marginal no setor. Só depois de ganhar uma licitação internacional no Peru, alvo de interesse também das concorrentes tradicionais, a Vamtec começou a se consolidar no mercado.

Uma vez consolidada a sua posição por meio de uma estratégia tradicional embasada em um raciocínio causal - política de preço baixo e busca de um nicho especifico-, a nova empresa deu um salto qualitativo com uma estratégia mais próxima ao raciocínio de desenho, a criação de uma nova dinâmica mercadológica mediante a proximidade física com os clientes:

A qualidade técnica do produto era similar e os preços relativamente padronizados, de forma que a única opção de criarmos um diferencial era ir para o lado dos principais clientes, Acesita e Usiminas; levamos a empresa de São Paulo a Timóteo (Minas Gerais) e passamos a ser literalmente o quintal da casa dos clientes, no Vale do Aço. Foi transcendental, obviamente, em termos de logística, mas também em termos de relacionamentos: eu passei, por exemplo, a levar os meus filhos no judô junto com os filhos dos meus clientes, e esse tipo de proximidade sempre ajuda. Sempre há certo bairrismo.

Observa-se que o empreendedor buscou não apenas extrair o máximo benefício dos relacionamentos preexistentes, como também construir novos relacionamentos durante o estágio de crescimento do projeto. Assim, a Vamtec acabou transformando o cenário -aparentemente imutáveldo seu setor de atividade por meio não de pesquisas tradicionais de mercado ou análises competitivas, e sim de parcerias estratégicas com clientes. 


\title{
5.4 PARCERIAS ESTRATÉgiCAS, FOCO NA AÇÃo E EXPLORAÇão DE CONTINGÊNCIAS
}

A empresa criada pelo empreendedor e seus sócios não se utilizou de pesquisas formais de mercado, e sim de consultas diretas com os potenciais clientes:

\begin{abstract}
$\mathrm{Na}$ época existiam apenas treze siderúrgicas no Brasil, que já eram clientes da empresa onde trabalhávamos. As visitamos, uma por uma, e perguntamos, simplesmente, se teriam interesse em ter a Vamtec como fornecedor. Tínhamos bons relacionamentos no mercado, graças aos serviços que prestávamos desde a empresa, e foi assim que nos transformamos em uma pedra no sapato dos concorrentes, até que chegou um momento em que não aguentaram mais.
\end{abstract}

Um dos clientes transformou-se em parceiro estratégico da Vamtec quando, nos estágios iniciais do empreendimento, aceitou produtos sem o padrão de qualidade adequado, com o propósito de estimular maior concorrência entre os fornecedores, que acabasse assim pressionando os preços para baixo. Esse tipo de parceria, com o foco na redução de custos, garantiu que a empresa superasse suas dificuldades iniciais:

A visão compartilhada dos sócios da empresa era não gastar o que não tínhamos. Viajávamos de ônibus entre São Paulo e Timóteo (Minas Gerais) para testar um produto na fábrica de um cliente e voltávamos no mesmo dia para não ter o gasto de pernoitar lá. Descarregávamos os caminhões pessoalmente para não pagarmos ajudantes. A ideia era minimizar os custos tanto quanto fosse possível.

Pode-se notar que o princípio effectual de perdas toleráveis -affordable loss (Sarasvathy, 2001; Sarasvathy; Dew, 2005; Dew et al, 2009)- guiou as decisões sobre investimentos dos empreendedores do Grupo Vamtec, em lugar do princípio causal tradicional de retorno esperado. Por outro lado, a priorização da ação em detrimento do planejamento conferiu agilidade à Vamtec, como se observa no trecho do discurso:

\footnotetext{
Não éramos de planejar, e sim de executar. Não tínhamos cronograma, o nosso planejamento era muito rudimentar. Mas isso nos deu muita flexibilidade: nosso planejamento de curto prazo permitia que mudássemos o foco rapidamente. Naqueles tempos, não perdíamos o tempo com metas não atingidas. Isso permitiu que, em apenas um ano, conseguíssemos testar os nossos produtos em $70 \%$ dos clientes e abaixar $50 \%$ o preço dos concorrentes).
}

A exploração de contingências para a transformação de problemas em oportunidades, um dos pilares do raciocínio effectual (Sarasvathy, 2001; Sarasvathy; Dew, 2005; Dew et al, 2009) pode ser observada também nesse caso, como se observa: 
Em razão de um acordo comercial com um cliente, temos a obrigação contratual de comprar dele 200 toneladas mensais de resíduos e subprodutos de carbono. Atualmente, temos 1.200 toneladas desses materiais nas instalações do cliente -esperando serem retiradas- e 2.780 toneladas no nosso próprio estoque, com um valor total de $\mathrm{R} \$ 2.230 .000$. Se tivéssemos aplicado os princípios básicos da administração, jamais teríamos feito esse negócio, porque contradiz a regra fundamental de manter estoque zero. Mas depois de várias pesquisas, acabamos encontrando uma possível aplicação desse material e calculamos que o novo produto permitirá aumentar em $25 \%$ o lucro da nossa planta da Bahia.

Observa-se também, no depoimento anterior, novamente a preferência pela ação mais do que pela pesquisa e sobre a análise competitiva formal, mesmo no atual estágio de evolução do Grupo Vamtec, em que, conforme a avaliação do seu fundador, o planejamento formal ganhou espaço em relação à antiga flexibilidade e velocidade de atuação. Essas transformações nas estruturas e nos processos, comentados por Read et al. (2011) na literatura, são decorrentes do crescimento da organização e, em geral, requerem maior utilização de raciocínios causais.

A figura 3 recria a mecânica proposta por Sarasvathy (2001) sobre o raciocínio effectual integrando os meios que o empreendedor dispunha no caso analisado:

Figura 3- Raciocínio effectual no caso Vamtec.

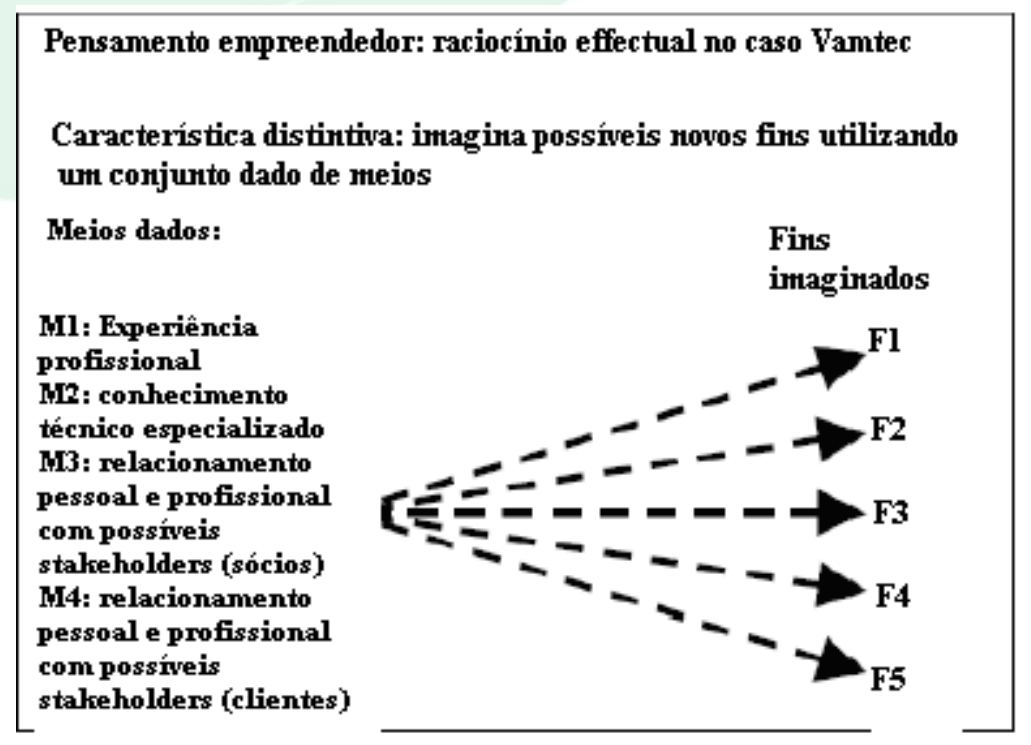

Dos três princípios fundamentais do raciocínio effectual (Sarasvathy, 2001), destacou-se no caso estudado a ênfase em parcerias estratégicas, mais do que na realização de pesquisas de mercado ou em análises competitivas tradicionais. Encontraram-se também exemplos de exploração de contingências, bem como a aplicação do princípio das perdas toleráveis durante os estágios iniciais do empreendimento. 
A preferência por uma lógica de desenho do que por uma lógica de decisão (Dew et al, 2008) foi observada em vários pontos dos relatos, principalmente na descrição daquele que acabaria sendo um dos rumos de ação mais determinantes para a consolidação comercial do empreendimento: a modificação da dinâmica mercadológica do setor pela busca da proximidade física com dois clientes importantes. Observou-se, nessa situação, uma intenção deliberada por parte da Vamtec de remodelar o seu ambiente local (Dew et al, 2008) por meio de uma intervenção direta nele.

Apresentam-se, a seguir, de forma sintética, os princípios do raciocínio effectual identificados no caso Vamtec, recriando com esse fim o contraste entre raciocínio causal e o effectual, proposto por Sarasvathy e Dew (2005):

\begin{tabular}{|c|c|c|c|}
\hline ASSUNTO & POSIÇÃO CAUSAL & $\begin{array}{c}\text { POSIÇÃO } \\
\text { EFFECTUAL }\end{array}$ & $\begin{array}{c}\text { RACIOCÍNIO EFFECTUAL } \\
\text { NO CASO VAMTEC }\end{array}$ \\
\hline Visão do futuro & $\begin{array}{l}\text { Predição. O futuro é } \\
\text { uma continuação do } \\
\text { passado e pode ser } \\
\text { razoavelmente previsto. }\end{array}$ & $\begin{array}{l}\text { Desenho. O futuro é } \\
\text { contingente às ações } \\
\text { propositais dos agentes. }\end{array}$ & $\begin{array}{l}\text { A Vamtec buscou e conseguiu } \\
\text { modificar a dinâmica } \\
\text { mercadológica do setor } \\
\text { (evitando, assim, que o futuro } \\
\text { fosse simples continuação do } \\
\text { passado) por meio da } \\
\text { proximidade física com os } \\
\text { clientes. }\end{array}$ \\
\hline Dados & Objetivos são dados & $\begin{array}{l}\text { Meios (quem eu sou, o } \\
\text { que eu sei, quem eu } \\
\text { conheço) são dados. }\end{array}$ & $\begin{array}{l}\text { O empreendedor partiu dos } \\
\text { meios disponíveis, e estes } \\
\text { determinaram as características } \\
\text { que deveria ter o } \\
\text { empreendimento. }\end{array}$ \\
\hline Agenda de decisão & $\begin{array}{l}\text { Recursos. Que recursos } \\
\text { devo acumular para } \\
\text { atingir os objetivos? }\end{array}$ & $\begin{array}{l}\text { Efeitos. Quais efeitos } \\
\text { posso criar com os } \\
\text { meios de que disponho? }\end{array}$ & $\begin{array}{l}\text { O core business do } \\
\text { empreendimento foi } \\
\text { determinado pelos } \\
\text { conhecimentos técnicos e } \\
\text { relacionamentos pessoais e } \\
\text { profissionais dos sócios. }\end{array}$ \\
\hline Bases do compromisso & $\begin{array}{l}\text { Deve. Faça o que você } \\
\text { deve fazer com base em } \\
\text { análises e } \\
\text { maximização. }\end{array}$ & $\begin{array}{l}\text { Pode. Faça o que você } \\
\text { é capaz de fazer com } \\
\text { base na imaginação e } \\
\text { na satisfação. }\end{array}$ & $\begin{array}{l}\text { Não houve pesquisa prévia de } \\
\text { mercado e sim a convicção } \\
\text { íntima do empreendedor de que } \\
\text { com os recursos humanos } \\
\text { disponíveis era possível o } \\
\text { empreendimento. }\end{array}$ \\
\hline $\begin{array}{l}\text { Aquisição de } \\
\text { stakeholders }\end{array}$ & $\begin{array}{l}\text { Visão instrumental dos } \\
\text { stakeholders. Os } \\
\text { objetivos do projeto } \\
\text { determinam quem } \\
\text { incorpora-se a le. }\end{array}$ & $\begin{array}{l}\text { Visão instrumental dos } \\
\text { objetivos. Quem é } \\
\text { incorporado ao projeto } \\
\text { determina seus } \\
\text { objetivos. }\end{array}$ & $\begin{array}{l}\text { Em todo momento, foram as } \\
\text { características dos sócios do } \\
\text { projeto que determinaram qual } \\
\text { deveria ser seu objetivo. }\end{array}$ \\
\hline
\end{tabular}




\begin{tabular}{|c|c|c|c|}
\hline Predisposição ao risco & $\begin{array}{l}\text { Retorno esperado. } \\
\text { Calcule o potencial } \\
\text { positivo e procure } \\
\text { (ajustando o risco) a } \\
\text { melhor oportunidade. }\end{array}$ & $\begin{array}{l}\text { Perdas toleráveis. } \\
\text { Calcule o potencial } \\
\text { negativo e arrisque } \\
\text { apenas o que está } \\
\text { disposto a perder. }\end{array}$ & $\begin{array}{l}\text { A redução de custos e o } \\
\text { nivelamento entre recursos } \\
\text { disponíveis e gastos foi um dos } \\
\text { compromissos mais fortemente } \\
\text { assumidos pelos sócios do } \\
\text { projeto. }\end{array}$ \\
\hline $\begin{array}{l}\text { Predisposição às } \\
\text { contingências }\end{array}$ & $\begin{array}{l}\text { Evitar. As surpresas } \\
\text { podem ser } \\
\text { desagradáveis. } \\
\text { Portanto, invista em } \\
\text { técnicas para evitá-las } \\
\text { ou neutralizá-las. }\end{array}$ & $\begin{array}{l}\text { Explorar. As surpresas } \\
\text { podem ser positivas. } \\
\text { Portanto, invista em } \\
\text { técnicas que são abertas } \\
\text { às surpresas e } \\
\text { transforme-as em novas } \\
\text { oportunidades. }\end{array}$ & $\begin{array}{l}\text { Conversão de dificuldades em } \\
\text { novas oportunidades de } \\
\text { negócio, mas também uma } \\
\text { aposta por sistemas de } \\
\text { padronização orientados para a } \\
\text { eliminação de surpresas na } \\
\text { operação do negócio } \\
\text { (raciocínio causal e effectual). }\end{array}$ \\
\hline
\end{tabular}

Quadro 2 - Princípios do raciocínio effectual no caso Vamtec.

\section{CONSIDERAÇOES FINAIS}

Observado à luz da lógica effectual (figura 2), o empreendimento analisado partiu da identidade, dos conhecimentos e dos relacionamentos profissionais de um empreendedor individual, que possuía um conjunto inicial de recursos, que foi acrescido do conhecimento dos stakeholders, que se incorporaram ao projeto ainda em sua fase embrionária. Dados os conhecimentos técnicos altamente especializados do empreendedor, que idealizou o negócio, o core business do empreendimento dificilmente poderia ter sido outro. Os compromissos entre os stakeholders viabilizaram a existência do novo negócio.

A partir de uma estreita relação entre o objetivo do empreendimento e os meios que o empreendedor dispunha na época -experiência profissional na empresa onde trabalhou, conhecimento técnico especializado e relacionamentos pessoais com outros especialistas e com potenciais clientes- foi possível compreender a criação de uma empresa com o mesmo objeto de negócio da empresa onde ele trabalhava, apesar do poder de mercado das organizações que dominavam o setor na época.

A análise do caso Vamtec propiciou uma visão da predominância do raciocínio effectual sobre o causal nos estágios iniciais de um empreendimento que foi criado a partir de uma situação de grande incerteza, como comenta Sarasvathy (2001), e, nesse caso, principalmente, em razão da concentração de grandes empresas no setor, tendo sido necessário aos empreendedores criar mercados ou identificar nichos nos quais as grandes empresas não impedissem as novas entrantes de se estabelecerem no mercado. 
Raciocínio Effectual e Raciocínio Causal na Criação de Novos Negócios: Um Estudo de Caso

Destaca-se, como limitação principal desse estudo, o seu caráter ex-post-facto, dado que os eventos analisados tiveram lugar na década de 1980. Pesquisas longitudinais que observem a criação de negócios enquanto o processo se desenvolve poderão melhor descrever a formatação de novo artefato empresarial. Por fim, estudos com outras etapas do processo empreendedor, que não apenas a criação, serão interessantes para confrontarem lógicas diferentes, a fim de compreender, por exemplo, o crescimento de pequenas empresas.

\section{REFERÊNCIAS}

Andrade, Maria M.(1994) Introdução à metodologia do trabalho cientifico. São Paulo: Atlas.

Augier, M., Sarasvathy, S. D.(2004) Integrating evolution, cognition and design: extending simonian perspectives to strategic organization. Strategic Organization, 2, 169-204.

http://dx.doi.org/10.1177/1476127004042843

Bauer, M., Gaskell, G. (2008) Pesquisa qualitativa com texto, imagem e som. 7. ed. Petrópolis: Vozes.

Cervo, A. L., Bervian, P.A.(2004) Metodologia científica. São Paulo: Makron Books.

Dew, N., Read, S., Sarasvathy, S. D., Wiltbank, R. (2008) Outlines of a behavioral theory of the entrepreneurial firm. Journal of Economic Behavior \& Organization. 66, 37-59.

http://dx.doi.org/10.1016/j.jebo.2006.10.008

Dew, N., Read, S., Sarasvathy, S. D., Wiltbank, R.(2009) Effectual versus predictive logics in entrepreneurial decision-making: differences between experts and novices. Journal of Business Venturing. 24, 287-309.

http://dx.doi.org/10.1016/j.jbusvent.2008.02.002

Gil, A.C. (2009) Como elaborar projetos de pesquisa. (4. ed.) - 12. reimp. - São Paulo: Atlas.

Malhotra, N.K.(2004) Pesquisa em marketing. Uma orientação aplicada. Porto Alegre: Bookman.

Read, S. et al. Effectual Entrepreneurship. London: Routledge, 2011.

Sarasvathy, S. D. What Makes Entrepreneurs Entrepreneurial? (2001) Recuperado em 14 de junho de 2010, de: http://ssrn.com/abstract=909038, 2001.

Revista Ibero-Americana de Estratégia - RIAE, São Paulo, v. 10, n. 2, p. 140-158, mai./ago. 2011. 
Juan Miguel Rosa González, Miguel Eduardo Moreno Añez \& Hilka Vier Machado

Sarasvathy, S. D., Dew, N. (2005) Entrepreneurial logics for a technology of foolishness. Scandinavian Journal of Management. 21, 385-406. http://dx.doi.org/10.1016/j.scaman.2005.09.009

Sarasvathy, S. D. (2003) Entrepreneurship as a science of the artificial. Journal of Economic Psychology. 24, 203-220.

http://dx.doi.org/10.1016/S0167-4870(02)00203-9

Simon, H.A.(1981) The Sciences of the Artificial. MIT Press, Cambridge.

Simon, H. A.(1991) Organizations and markets. Journal of Economic Perspectives. 5(2), 25-44.

Simon, H. A.(1993) Strategy and organizational evolution. Strategic Management Journal. 14, $131-42$.

http://dx.doi.org/10.1002/smj.4250141011

Simon, H. A.(1997) An empirically based microeconomics. New York and Melbourne: Cambridge University Press.

Venkataraman, S.(1997) The distinctive domain of entrepreneurship research. In J. Katz \& R. Brockhaus (Eds.), Advances in entrepreneurship, firm emergence, and growth. Greenwich, CT: JAI Press, 3, 119-138.

Vergara, S.C.(2004) Projetos e relatórios de pesquisa em administração. (5 ed.) São Paulo: Atlas.

Wiltbank, R., Dew, N., Read, S., Sarasvathy, S. D. (2006) What to do next? The case for nonpredictive strategy. Strategic Management Journal. 27, 981-998.

http://dx.doi.org/10.1002/smj.555

Yin, R. K.(1994) Case study research: design and methods. (2. ed.) California: Sage.

Recebido: 09/06/2011

Aprovado: 25/08/2011

Revista Ibero-Americana de Estratégia - RIAE, São Paulo, v. 10, n. 2, p. 140-158, mai./ago. 2011. 